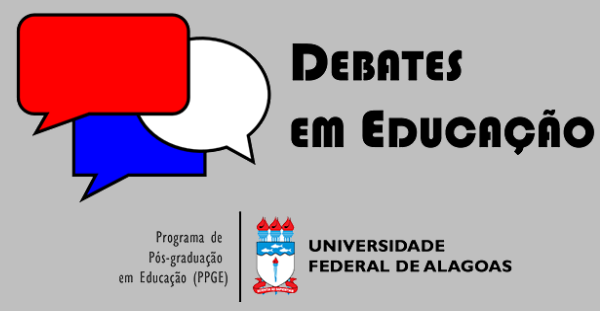

ISSN Eletrônico 2175-6600

Vol. 13 I Número Especial 2 I 2021

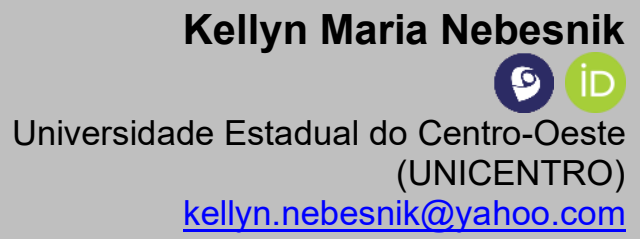

Elisa Aguayo da Rosa

( $\theta$ iD

Universidade Estadual do Centro-Oeste

(UNICENTRO)

elisadarosa@unicentro.br

\section{DESENVOLVIMENTO E AVALIAÇÃO DE CASOS PARA O ENSINO DE MECANISMO DE REAÇÃO}

\section{RESUMO}

Casos são narrativas utilizadas para ensinar e que aproximam o conteúdo ao cotidiano e/ou às situações profissionais dos alunos, conferindo-lhes um papel ativo na aprendizagem e maior capacidade de resolver problemas. Nessa perspectiva, o objetivo deste trabalho foi desenvolver casos sobre mecanismos de compostos carbonilados, para uso na graduação. Livros e artigos inspiraram as temáticas para compor os casos que foram avaliados por professores universitários, via questionário. Os resultados evidenciaram que os temas selecionados foram propícios para criar narrativas e relacioná-los às reações químicas. Os docentes mencionaram que têm interesse em aplicar os casos em suas aulas e que perceberam a importância desse método para promover autonomia, contextualização e para colocar os alunos no centro do processo de ensino e aprendizagem. No entanto, não deixaram de refletir que a implementação dos casos exige tempo, habilidade docente e receptividade dos alunos, para que resulte efetiva.

Palavras-chave: Compostos Carbonilados; Casos; Ensino Superior.

\section{DEVELOPMENT AND EVALUATION CASES FOR TEACHING REACTION MECHANISM}

\begin{abstract}
Cases are narratives used to teach and to bring the content closer to the students' daily life or professional situations, giving them an active role in learning and greater ability to solve problems. In this perspective, the objective of this work was to develop cases about mechanisms of carbonyl compounds, for use in graduation. Books and articles inspired the themes to compose the cases that were evaluated by university teachers, through a questionnaire. The results showed that the selected themes were effective to creating narratives and relating them to chemical reactions. The teachers mentioned that they are interested in applying the cases in their classes and that they realized the importance of this method to promote autonomy, contextualization and to place students at the center of the teaching and learning process. However, they did not fail to reflect that the implementation of the cases requires time, teaching ability and students receptivity, for it to be effective.
\end{abstract}

Keywords: Carbonyl compounds. Cases. University Education.

Submetido em: 29/10/2020

Aceito em: 01/06/2021

Publicado em: 30/11/2021

do https://doi.org/10.28998/2175-6600.2021v13nEsp2p816-841 


\section{Introdução}

Diante de um processo educacional que demanda criatividade, reflexão, iniciativa e capacidade de resolver problemas, é impreterível que o aluno domine um conjunto de conhecimentos, habilidades e atitudes (NICOLINE, 2003; CHIAVENATTO, 2006).

De acordo com Zabala e Arnau (2010), o conhecimento só adquire sentido quando aquele que o possui é capaz de utilizá-lo. Assim sendo, o papel do ensino deve orientarse em torno da formação integral e da educação para a vida, de modo que os alunos sejam capazes de responder eficazmente aos diversos tipos de situações com as quais se depararem no futuro. Perrenoud (2002), por sua vez, frisa que a principal ideia é confrontar o estudante com situações semelhantes àquelas que ele encontrará no trabalho e construir saberes, a partir dessas circunstâncias, ou seja, em outras palavras, é necessário adaptar a abordagem dos problemas à natureza das profissões.

Vale ressaltar que se educa com uma finalidade, que não é imediata, mas com o propósito de que o que agora é ensinado e aprendido, em um contexto escolar, possa, no momento certo, ser utilizado na realidade e na ocasião profissional em que esses conhecimentos, habilidades ou atitudes aprendidas se façam necessários (ZABALA; ARNAU, 2010).

Diante disso, é fundamental que se privilegie o ofício e a importância do estudante no processo da aprendizagem, em que o papel do professor, de "ensinar coisas e soluções", passe a ser "ensinar o estudante a aprender coisas e soluções", ou seja, que o aluno seja estimulado a buscar o conhecimento por si só; aprenda a questionar as situações; sistematizar problemas e buscar criativamente as soluções (BRASIL, 2001). Por conseguinte, é aconselhável que profissionais de ensino estimulem a autonomia dos alunos, possibilitando-Ihes que aprendam a aprender e auxiliando-os a encontrarem sentido para seu trabalho (ZABALA; ARNAU, 2010).

Nessa perspectiva, Herreid (2004) reflete que a melhor forma de aprimorar a capacidade de uma pessoa, em Química, é por intermédio de problemas químicos. E os estudos de caso, ou simplesmente casos, contemplam essa reflexão. Casos são conhecidos como narrativas cujos personagens enfrentam decisões ou dilemas (SÁ, 2006) que, quando aplicados para ensinar, motivam os alunos a compreenderem os fatos que permeiam a história e a solucionarem um problema.

O método do estudo de casos já é adotado em muitos cursos de nível superior, como Medicina e Direito. Também há divulgações de aplicação de casos, em curso de formação inicial em Química (MASSENA, FILHO, SÁ, 2013; SÁ, KASSEBOEHMER, 
QUEIROZ, 2013). Assim sendo, este trabalho apresenta essa abordagem no ensino de Química Orgânica, em especial por meio do tema Compostos Carbonilados, pois, além de ser um tópico presente na ementa da disciplina, da área, em cursos de graduação, ainda é importante para a melhor compreensão do cotidiano; afinal, há uma variedade de espécies carboniladas presentes nos alimentos, nos aromas de flores e frutos, sabões, vitaminas, polímeros, fármacos, entre outros.

Ainda em relação à Química Orgânica, em educação de nível superior, não se pode deixar de comentar a necessidade de os alunos estudarem os mecanismos das reações, a fim de compreenderem de que forma e quais parâmetros condicionam a formação dos compostos orgânicos. Ademais, poder oferecer ao aluno um método de ensino em que a solução de um caso passa pela busca do mecanismo de reação, poderá dar uma ressignificação ao aprendizado destas sínteses, valorizando sua importância.

Diante desse contexto, o objetivo principal deste trabalho foi desenvolver dois casos para motivar o ensino de mecanismo de reação, de compostos carbonilados. $\mathrm{Na}$ sequência, houve o intuito de diagnosticar se professores, que atuam na disciplina de Química Orgânica, em cursos de graduação, adotariam os casos como material didático e como analisariam suas características positivas e negativas.

\section{Revisão bibliográfica}

\subsection{Os estudos de caso}

John Dewey, filósofo e pedagogo americano, propôs, no início do século $\mathrm{XX}$, o conhecido inquiry learning ou ensino por investigação (TROPIA, 2011). Nessa abordagem, os alunos participam do processo de construção conceitual, permitindo-lhes que argumentem e exercitem a razão, ao invés de se depararem com respostas prontas e acabadas, que trazem uma visão equivocada das ciências (CARVALHO, 2004).

Nessa linha investigativa, no final da década de 1960, a metodologia intitulada Problem Based Learning ( $P B L$ ) ou Aprendizagem Baseada em Problemas (ABP) surgiu na Escola de Medicina, da Universidade de McMaster, Canadá, e logo se difundiu por outros países. Sobretudo, despontou como uma tentativa de superar a falha do distanciamento do ensino em relação aos contextos profissionais reais. (BOUD; FELETTI, 1997; FREITAS, 2012).

Tal método utiliza problemas como ponto de partida para os alunos integrarem novos conhecimentos, em oposição ao ensino que, primeiramente, introduz os conceitos 
e, em seguida, aplica o problema (BARROWS, 1986; DUCH, 1996). Assim sendo, a PBL é "uma técnica de ensino que educa apresentando aos alunos uma situação que leva a um problema que tem de ser resolvido" (DELISLE, 2000, p. 5, apud SOUZA; DOURADO, 2015

O Estudo de Caso, por sua vez, é uma variação da PBL. Foi criado no Século XIX, por Christopher Columbus Langdell, na Universidade de Havard, para ser utilizado no ensino dos advogados, juristas e administradores de empresa. (MENEZES, 2009). Sucintamente, os casos são empregados visando ensinar habilidades de tomada de decisões profissionais, ou, em outras palavras, têm "o intuito de colocar os alunos em contato com problemas reais, de estimular o desenvolvimento do pensamento crítico, a habilidade de resolução de problemas e a aprendizagem de conceitos da área em questão" (SÁ; QUEIRÓZ, 2010, p.1).

Especificamente, os casos são histórias que envolvem e ensinam (HERREID, 2005 e 2007). De acordo com Sá, Francisco e Queiróz (2007), as narrativas apresentam indivíduos enfrentando decisões ou dilemas, de modo que o aluno é incentivado a compreender os fatos e contextos envolvidos na história, a fim de solucionar o problema em questão. Nesse sentido, o papel principal do professor consiste em auxiliar o estudante a trabalhar com os fatos e a análise do problema, bem como, com as possíveis soluções.

Um aspecto importante dos casos é o fato de ser um método flexível, isto é, pode ser utilizado em uma série de situações e, ainda assim, explorar diversos conteúdos. Todavia, para que as necessidades do ensino sejam alcançadas, a escolha do assunto do caso deve ser relevante no contexto da disciplina. Os alunos também devem estar aptos a enfrentar, tanto no que diz respeito ao conhecimento do conteúdo científico, quanto àquele sobre questões éticas, sociais e econômicas abarcadas no caso (SÁ; FRANCISCO; QUEIRÓZ, 2007). Em vista disso, alguns dos aspectos que devem ser considerados para a elaboração de um bom caso, conforme descritos na literatura, são: narrar uma história; despertar o interesse pela questão; ser atual; produzir empatia em relação aos personagens; ser relevante ao leitor; ter utilidade pedagógica; provocar um conflito; forçar uma decisão; ser curto (HERREID, 1997).

Ademais, no que se refere à aplicação dos casos, Herreid (1998) sugere, desde o formato de aula expositiva, em que a história é contada pelo professor; o formato de discussão, em que alunos são indagados a respeito das suas perspectivas e opiniões com relação à resolução do caso; até o formato de atividades em pequenos grupos, de maneira que os estudantes trabalhem em colaboração. Dentre outros, existe o formato em 
que o professor fornece aos alunos um caso que realmente foi enfrentado por determinados pesquisadores (SÁ; FRANCISO; QUEIROZ, 2007).

Diante do exposto, o método dos casos tem implicações favoráveis porque mostra como é fazer ciência, ou seja, ensina a coletar informações, trabalhar com dados incompletos, criar e refinar hipóteses, fazer previsões, etc. (HERREID, 2004). Vale salientar que o ensino orientado por vias PBL foi adotado por várias áreas do conhecimento e níveis da educação, consolidando-se, assim, como um método de aprendizagem, considerado eficaz nas mais diversas instituições de ensino e pesquisa em todo o mundo (SOUZA; DOURADO, 2015).

\subsubsection{Casos em Química Orgânica}

Em se tratando de casos que podem ser úteis para o ensino e a aprendizagem de Química Orgânica, no Ensino Superior, na literatura, há alguns referenciais. Como exemplo, no artigo Thalidomide makes a comeback: a case discussion exercise that integrates biochemistry and organic chemistry revela-se um caso sobre a comercialização do medicamento Talidomida. O objetivo dos autores era estimular, além da aprendizagem de conteúdos científicos, o pensamento crítico dos alunos, por meio da análise dos riscos e benefícios envolvidos na distribuição deste medicamento (BENNETT; CORNELY, 2001). Para solucionar o referido caso, os alunos deveriam buscar, entre outros, conhecimentos em estereoquímica e hidrólise de amida.

Similarmente, o artigo Molecular modelling in the undergraduate chemistry curriculum: the use of beta-lactams as a case study, articula as áreas de Química e de Bioquímica e introduz conceitos de modelagem molecular e química computacional (RINGAN; GRAYSON, 1994). Já o artigo Estudo de casos sobre a química dos carboidratos: contribuições para a formação profissional dos estudantes de química da UFRGS, conforme o próprio título sugere, aborda uma experiência desenvolvida com casos, na disciplina de Química Orgânica de Biomoléculas, para o ensino de carboidratos (PASSOS, 2016).

No Brasil, o Grupo de Pesquisa em Ensino de Química do Instituto de Química de São Carlos (http://www.gpeqsc.com.br/casos/casos.php) disponibiliza casos para o ensino de Química e áreas afins. São casos de caráter sócio científico e alguns podem ser inseridos em disciplinas de Química Orgânica, para a discussão de reações. Como exemplo, há o caso intitulado Óleo de Fritura - Descarte Consciente, que possibilita a abordagem das funções do álcool, ácido carboxílico e ésteres, e as reações de 
saponificação e transesterificação. Há, ainda, outros dois casos: A loira perigosa e Pet: soluções ideais para um problema real, que promovem a busca por reações de esterificação, transesterificação e mecanismos para a interconversão das funções orgânicas.

\subsection{Os compostos carbonilados}

Compostos carbonílicos são moléculas orgânicas que possuem uma dupla ligação entre um átomo de carbono e um átomo de oxigênio, conforme grupo funcional $\mathrm{R}_{2} \mathrm{C}=\mathrm{O}$, da Figura 1 (VIEIRA; REBOUÇAS; ANDRADE, 2012).

A reatividade das substâncias carboniladas reside na polaridade da ligação dupla carbono-oxigênio. $O$ átomo de oxigênio é mais eletronegativo que o de carbono e isso torna o carbono carbonílico muito eletrofílico e ávido por espécies nucleofílicas, ao passo que o oxigênio é nucleofílico e ligeiramente básico (Figura 1) (BRUICE, 2006). Além disso, o grupo carbonila possui um átomo de oxigênio com dois pares de elétrons não ligantes, que confere à carbonila a característica de base de Lewis fraca (VOLHARDT, 2013).

Figura 1: O grupo carbonila e suas regiões nucleofílica e eletrofílica.

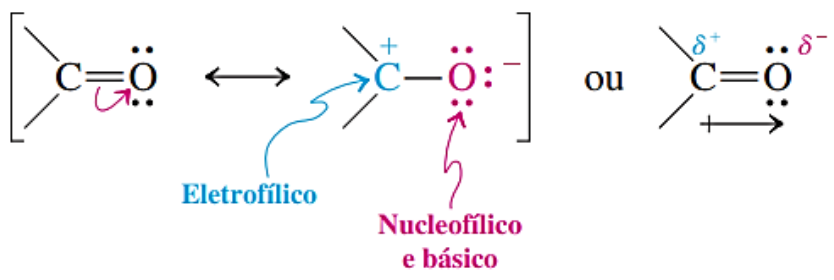

Fonte: Volhardt, 2013.

Uma vez que a carbonila é muito versátil, destacam-se diferentes possibilidades de reações para esse grupo funcional. As reações de substituição nucleofílica acílica, por exemplo, ocorrem quando um nucleófilo troca um substituinte ligado ao grupo acila $(\mathrm{RC}=\mathrm{O})$, no reagente, para formar produtos de substituição. Trata-se de uma reação que ocorre em duas etapas: formação e colapso do intermediário tetraédrico (Figura 2). Entretanto, para que a reação de fato ocorra, o nucleófilo atacante não deve ser uma base muito mais fraca do que o grupo que será substituído. Isso ocorre no grupo carbonílico, de um ácido carboxílico, ou um derivado de ácido, que possui um grupo de 
saída, base fraca, que pode ser substituído por outro grupamento, o nucleófilo (BRUICE, 2006).

Figura 2: Reação de Substituição Nucleofílica Acílica.

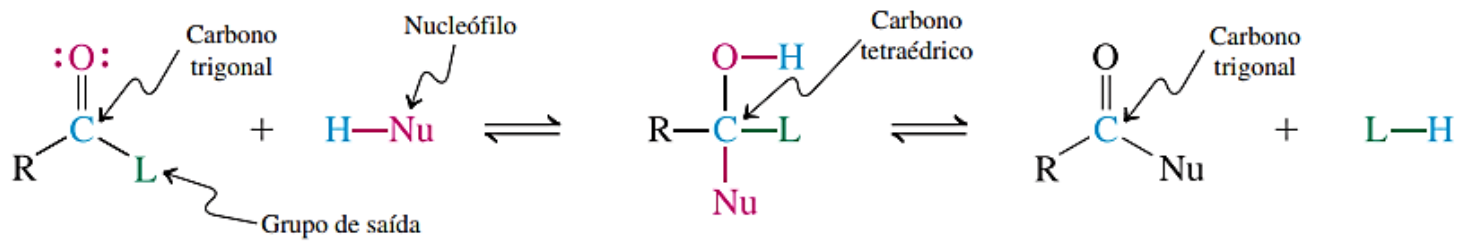

Fonte: Volhardt, 2013.

Por outro lado, o grupo carbonílico de um aldeído ou cetona está ligado a grupos que são bases muito fortes para serem eliminados em condições normais, por isso não podem ser substituídos por outros grupos. Logo, os aldeídos e as cetonas reagem com nucleófilos para formar produtos de adição, ao invés de substituição (BRUICE, 2006).

A maior parte das reações dos aldeídos e cetonas ocorre em três posições: o oxigênio, como base de Lewis; o carbono da carbonila, como eletrófilo; o carbono "alfa" adjacente à carbonila (Figura 3 ).

Figura 3: Regiões reativas de cetonas (ou aldeídos).

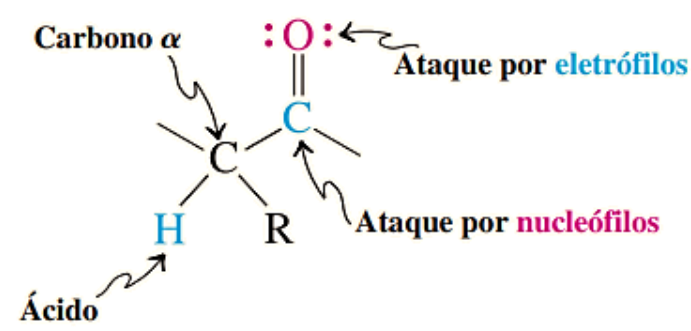

Fonte: Volhardt, 2013.

Dessa forma, quando se trata da adição de nucleófilos fortemente básicos aos grupos carbonila, normalmente é seguido o mecanismo de adição nucleofílica/protonação (Figura 4). 
Figura 4: Adição nucleofílica/protonação (condições básicas).

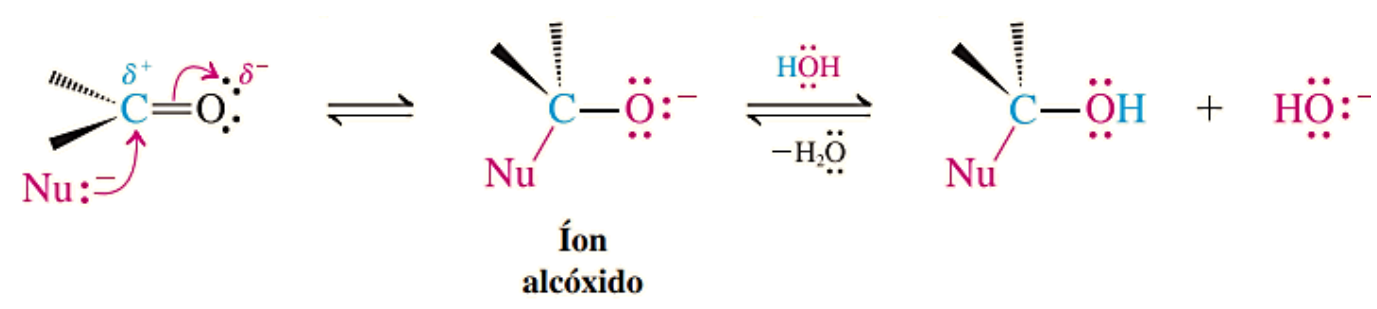

Fonte: Volhardt, 2013.

Já em reações com nucleófilos relativamente pouco básicos, o mecanismo de protonação/adição eletrofílica é mais eficiente, visto que as condições ácidas são incompatíveis com nucleófilos fortemente básicos, pois eles seriam protonados (Figura 5) (VOLHARDT, 2013).

Figura 5: Protonação/adição nucleofílica (condições ácidas).

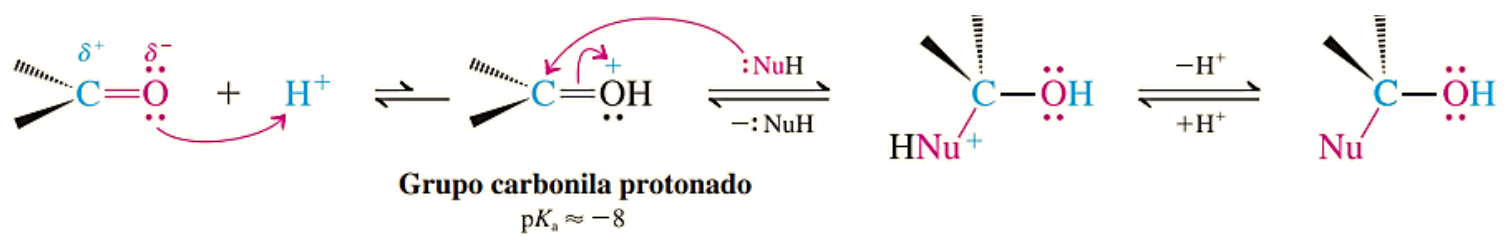

Fonte: Volhardt, 2013.

Ademais, dentre os compostos orgânicos de odores mais potentes e variados estão também as moléculas pertencentes ao grupo carbonila (VOLHARDT, 2013). Os compostos carbonílicos de baixa massa molar encontram-se bastante difundidos na natureza e são comumente absorvidos pelo homem, a partir da inalação de seus vapores, absorção cutânea ou ingestão. Entre esses compostos há os que são irritantes para os olhos, para a pele e trato respiratório, e alguns apresentam características fitotóxicas, teratogênicas, mutagênicas e carcinogênicas (ANDRADE et. al., 2002). Em alimentos e bebidas, em particular, a incidência desses compostos é comum, podendo influenciar significativamente na sua qualidade (AZEVÊDO et. al., 2007).

\section{Metodologia}

A metodologia empregada neste estudo focalizou a abordagem qualitativa, que é apoiada em características fenomenológicas e, assim sendo, preocupa-se com o significado dos fenômenos e do processo social, ou seja, com as crenças, os valores e/ou 
representações sociais (PÁDUA, 1997). Nesse tipo de pesquisa não é exigido o uso de métodos e técnicas estatísticas (MORESI, 2003).

Esta pesquisa ainda está fundamentada nos referenciais de Sá e Queiroz (2010), Herreid (1998, 2004, 2005, 2007) e Silva e Nuñez (2002), que tratam do ensino por problemas ou casos.

Assim, a construção e a avaliação dos casos foram desenvolvidas por meio dos momentos 1 a 3 , descritos a seguir:

Momento 1: seleção de temas relevantes do cotidiano e que mostrassem articulação com os compostos carbonilados, para criar o cenário da narrativa e a busca por um mecanismo de reação. Essas temáticas foram inspiradas em livros de Química Orgânica, de nível superior, e em outros meios de informação, como artigos, livros paradidáticos e/ou notícias disponíveis nas mídias.

Momento 2: etapa em que os casos foram desenvolvidos, de acordo com as orientações de Sá e Queiroz (2010, p.23) - "escolha o assunto principal a ser destacado no caso; elabore uma lista com todos os conceitos e habilidades que se pretende abordar através da aplicação do caso; elabore uma lista de possíveis personagens do caso; elabore uma série de questões para discussão em aula".

Momento 3: concretização da avaliação do material didático construído, de acordo com os seguintes itens.

i) Amostragem: docentes que atuam em cursos de graduação, em disciplinas de Química Orgânica, de Instituições de Ensino Superior, no Paraná.

ii) Considerações éticas: a pesquisa foi cadastrada na Plataforma Brasil e enviado ao Comitê de Ética em Pesquisa, da Universidade Estadual do Centro-Oeste, sendo aprovada, mediante o Parecer $n^{\circ}$ 3.663.145 e Certificado de Apresentação de Apreciação de Ética (CAAE) n 23655219.8.0000.0106. Em seguida, o projeto foi encaminhado às instituições coparticipantes, do Estado do Paraná, pelos pareceres $n^{\circ} 3.723 .811,3.674 .476,3.739 .608$ e 3.744.314; e certificados, CAAE: 23655219.8.3002.5231, 23655219.8.3001.0105, 23655219.8.3005.8156 e 23655219.8.3006.0102; respectivamente.

iii) Procedimentos e instrumentos para coleta e análise de dados: o primeiro passo para o recrutamento dos sujeitos da pesquisa foi contatar as coordenações dos cursos de Química do Paraná. Quando houve o retorno da carta de anuência, alguns destes chefes ou coordenadores de curso já sugeriram o nome de um docente que poderia contribuir com a pesquisa, 
porque ministrava aulas de Química Orgânica. O passo seguinte foi enviar, por e-mail, para os professores indicados, o Termo de Consentimento Livre e Esclarecido - TCLE, o material didático produzido e um questionário para coleta dos pareceres avaliativos. O questionário foi desenvolvido via programa Formulários Google e contava com seis perguntas.

Neste trabalho, deu-se ênfase apenas ao questionamento sobre a viabilidade do uso dos casos e suas características positivas e negativas e, para analisar as repostas do questionário, seguiu-se a metodologia da Análise de Conteúdo, proposta por Bardin (1979), que contempla as etapas: pré-análise do material; exploração e categorização do que foi percebido no conteúdo e interpretação dos resultados.

\section{Resultados e discussões}

\subsection{Os casos}

Dos dois casos desenvolvidos e socializados neste trabalho, um trata da temática de um fármaco e uma reação de acilação (Caso 1) e o outro é sobre biodiesel e uma reação de transesterificação (Caso 2). Destacamos, a seguir, os casos e um breve comentário sobre a solução e representação do mecanismo de reação, os quais devem ser buscados pelos alunos, com a tutoria do professor, de modo a atenderem o que foi proposto nas narrativas.

\section{Caso 1}

Fonte de inspiração: ENGEL, R. G. et al. Química Orgânica Experimental: técnicas de escala pequena. Tradução da $3^{a}$ edição norte-americana. São Paulo: Cengage Learning, 2012. Analgésicos, p. 864-868.

Heitor era um profissional muito qualificado e formado em Química pela Universidade de Harvard, em 1886. Desde então, trabalhava numa empresa do ramo farmacêutico, onde, devido a sua notável competência e excelente desempenho, avançava hierarquicamente, desde que foi efetivado.

Certo dia, no ano de 1887, Arthur, o diretor de pesquisas da empresa, deparouse com o seguinte problema: como se livrar de aproximadamente 50 toneladas de paminofenol, um subproduto oriundo de uma das sínteses químicas da companhia. Preocupado que essa eliminação fosse realizada de maneira rentável, Arthur resolveu conversar com o químico Heitor para decidirem como proceder. 
$\mathrm{Na}$ época, Arthur iniciou a conversa.

_ Heitor, como você deve ter percebido, a quantidade de p-aminofenol está aumentando excessivamente. Acredito que deveríamos encontrar uma maneira vantajosa de nos livrarmos desse subproduto.

Ligeiramente, Heitor respondeu:

_ Que tal tentarmos convertê-lo em um composto com estrutura similar, para depois verificarmos sua potencialidade como novo fármaco?

O diretor, então, questionou:

_ Você tem alguma sugestão em vista?

Heitor pensou por alguns minutos e prosseguiu:

_ Transformá-lo em acetaminofeno, quem sabe! Porém, devemos levar em conta que esse composto ainda é fenólico, e o fenol é considerado tóxico.

Arthur, por sua vez, rebateu:

_ Poxa! E não há solução para isso?

Ao passo que o químico articulou:

_ $O$ único jeito seria retirar essa hidroxila do acetaminofeno.

Naquele momento, Heitor não conseguiu mais prosperar sobre o assunto, nem esclarecer que produto poderia ser formado. Contudo, como era necessária uma solução, urgentemente, e tendo imensa confiança nas habilidades químicas de Heitor, Arthur deixou a missão para o químico.

Você é o Heitor e está no século XIX. Demonstre como resolveria esse impasse, destacando os passos reacionais, a partir do p-aminofenol.

Para desenrolar o referido caso, deve-se levar em conta que o interlocutor da questão está no século XIX, no ano de 1887, quando ainda não se conhecia o poder analgésico do paracetamol (que se confirmou um pouco mais adiante, em 1893) e quando, também, conforme suposição da narrativa, não se considerava ter grupos fenóis em medicamentos, em razão de sua toxicidade. Assim, sugere-se ao professor chamar a atenção para a estrutura química da fenacetina, que não carrega o grupo hidroxila no anel aromático. Portanto, partindo do $p$-aminofenol, uma opção é efetuar sua acetilação de modo a isolar o acetaminofeno. Isso se dá reagindo a região da molécula que contém o grupo amina, que realiza um ataque nucleofílico sobre o carbono carbonílico polarizado do anidrido acético (também poderia ser empregado cloreto de acila). Este, por sua vez, apresenta um bom grupo abandonador, que formará o ácido acético, um subproduto da 
reação. Após, via reação de substituição nucleofílica bimolecular $\left(S_{N} 2\right)$, empregando um haleto de alquila primário, é conduzida a formação do produto desejado, a fenacetina (Figura 6). Desse modo, é possível converter o $p$-aminofenol em um novo produto, que foi amplamente usado como analgésico e antitérmico antes de ser substituído pelo paracetamol.

Figura 6: Mecanismo de reação para o Caso 1.

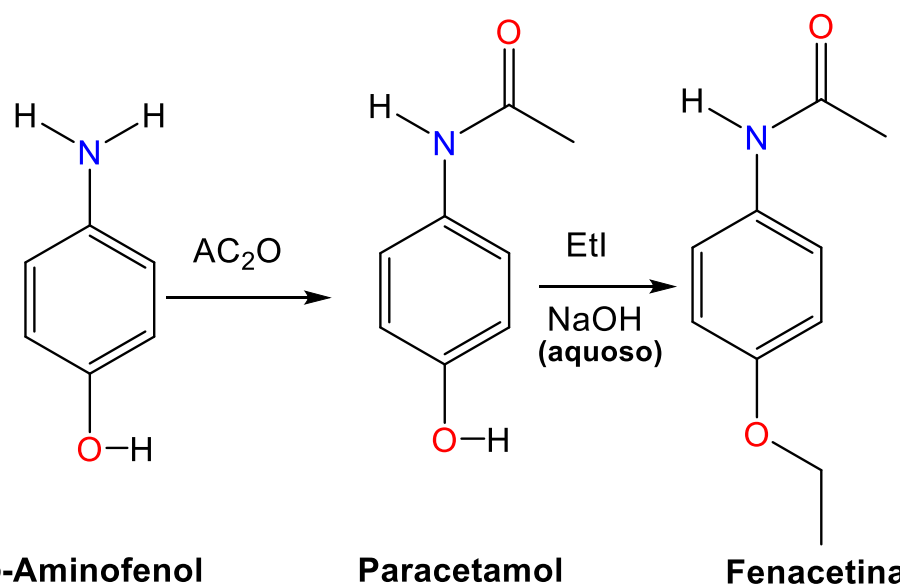

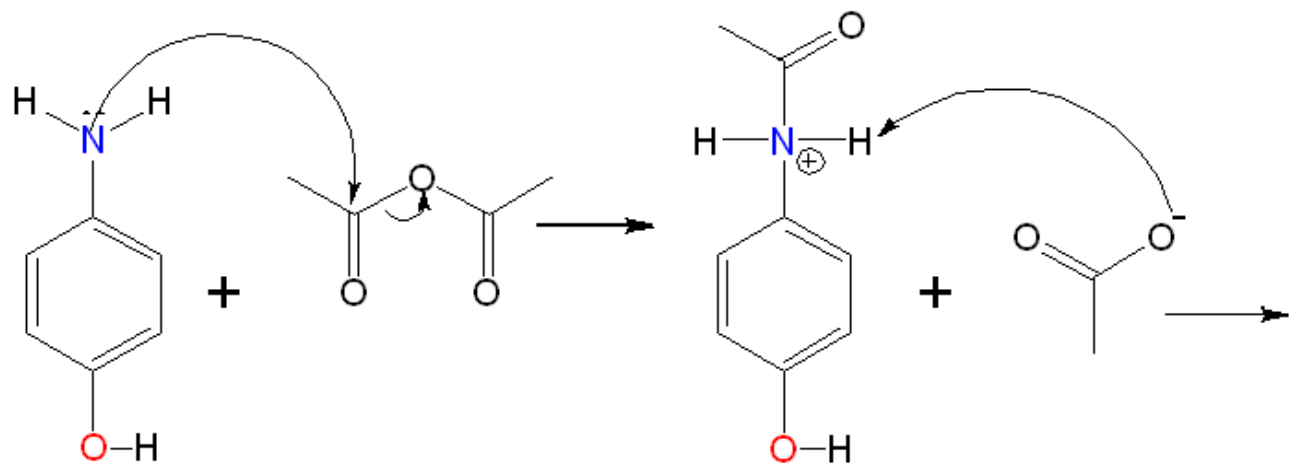

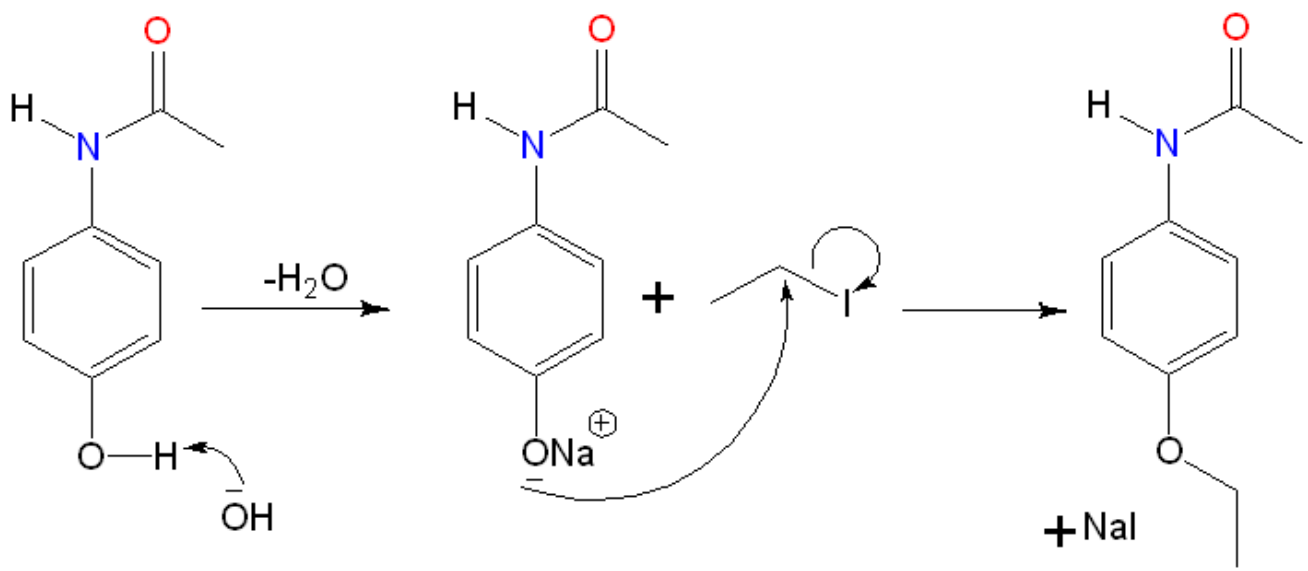

Fonte: Elaborada pelos autores (2020). 


\section{Caso 2}

Fonte de inspiração: ENGEL, R. G. et al. Química Orgânica Experimental: técnicas de escala pequena. Tradução da $3^{a}$ edição norte-americana. São Paulo: Cengage Learning, 2012. Biocombustíveis, p. 918-921.

No início do projeto de Iniciação Científica, IC, do aluno Valdo (V), sobre a produção de um biodiesel, o orientador sugeriu que, primeiramente, ele se inteirasse do assunto, na literatura, para breve debate sobre o tema. Convicto de que devia fazer um bom trabalho, trocou algumas ideias com o seu colega $(C)$ de república.

(V) _ Cara, você se lembra da aula de Orgânica que tivemos ontem?

(C) _ Mais ou menos.

(V) _ A professora falou lá sobre os ésteres. Vou usar isso na IC para produzir um biodiesel.

(C) _ Que legal cara!!! Para biodiesel é aquela reação de éster com álcool?

(V) _ É. Mas não sei se vou usar metanol ou etanol. Será que coloco o álcool em excesso?

(C) _ Mas tem grande importância isso?

(V) _ Há de ter, velho!!! E lembra que tem a reação com catálise ácida ou básica?

(C) _ Lembro. Acho que uma delas é mais lenta e de menor rendimento. E qual éster você vai usar?

(V) _ O professor disse que tem um estoque de óleo de soja.

(C) _ Cara, agora veio na cabeça que ter muita água no meio não é bom.

(V) _ Não sei explicar isso.

(C) _ Tem aquele lance de formar ácido graxo ou talvez sabão, que também não é bom.

(V) _ Eita! E agora? Como preparo esse biodiesel? Vou trocar uma ideia com o João. Ele já cursou as disciplinas de Química Orgânica e faz tempo que está lá no laboratório de pesquisa.

(C) _ Põe tempo nisso! Quem sabe esse ano ele se forma.

Nesta história você é o João. Ajude o Valdo neste drama da IC.

A formação do biodiesel, conforme diálogo, aponta para a transformação de um éster com álcool, conhecida como reação de transesterificação. Essa transformação pode ocorrer via catálise ácida ou básica. As condições básicas, via uso de hidróxido de sódio $\mathrm{NaOH}$ (Figura 2), por exemplo, é mais utilizada, tendo em vista que a reação é mais 
rápida, $-\mathrm{OH}$ é um melhor nucleófilo e a reação resulta em maior rendimento, se comparada às condições ácidas. $O$ excesso do álcool como solvente é empregado devido ao caráter reversível da reação, de modo que mais álcool é necessário para aumentar o rendimento do éster. Por sua vez, a água, formada durante a reação ou presente nas matérias-primas, conduz à hidrólise de alguns ésteres, com posterior saponificação dos ácidos graxos livres. Uma saída para evitar essa formação é empregar diretamente os alcóxidos de sódio ou potássio, como catalisadores da reação, ao invés do hidróxido de sódio. Quanto ao álcool, industrialmente o metanol é mais utilizado por não ser higroscópico, embora seja altamente tóxico. Entretanto, o uso de etanol na produção de biodiesel é atrativo sob o ponto de vista estratégico e ambiental, já que o Brasil é o maior produtor mundial desse álcool, que possui características favoráveis, como baixa toxicidade e produção a partir de fontes renováveis (cana de açúcar). 
Figura 7: Mecanismo de reação para o Caso 2.

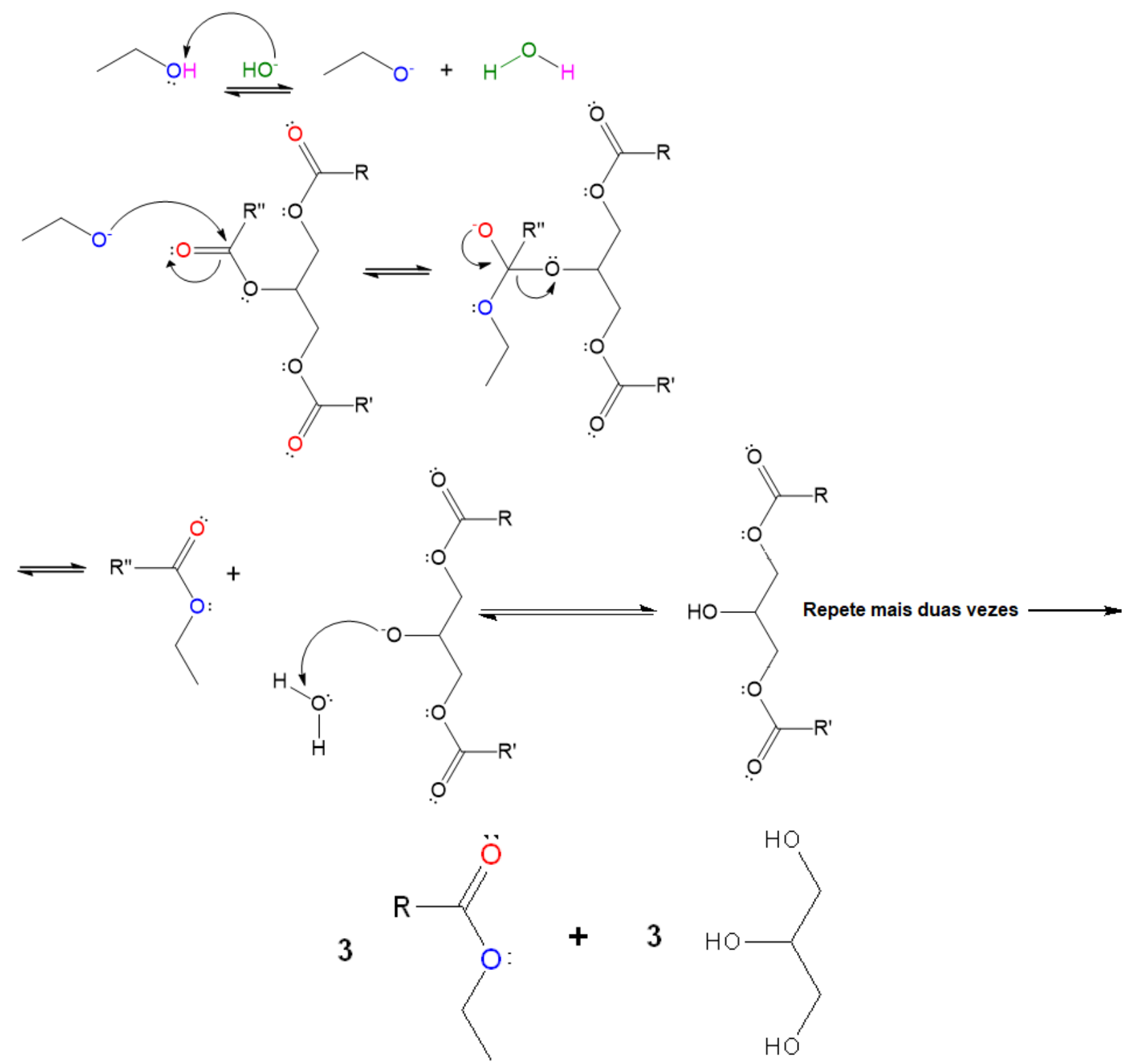

Fonte: Elaborada pelos autores (2020).

Para a aplicação desse material, sugere-se fazer uso do formato de discussão ou atividades em pequenos grupos. De qualquer forma, é aconselhável que o professor conduza o aluno ou os grupos de alunos à leitura do caso e, ao final do processo, à representação e explicação do mecanismo da reação, que atende a solução do problema exposto. Nesse meio, sugere-se, também, com base em Sá e Queiroz (2010), que o professor estimule alguns questionamentos, tais como: do que se trata esse caso ou qual é o problema e o tema que estão em evidência? Por onde começamos a solucionar ou o que precisamos saber e/ou buscar? Questionar as ideias prévias dos alunos também é 
recomendado (SILVA E NÚÑEZ, 2002). Na sequência, livros didáticos, artigos, internet, entre outros meios de informação e comunicação deverão estar disponíveis para consulta e busca da solução. O professor deverá exercer, então, um papel de tutor e, em sala de aula, percorrer entre os alunos, a fim de ouvir suas escolhas, tirar dúvidas, sugerir caminhos, etc. Momentos de debates atentos com todos os alunos também são bemvindos, bem como conduzir os alunos a mostrarem as informações encontradas ao longo da busca.

Ressalta-se, ainda, que são variados os questionamentos referentes ao mecanismo de reação, que deverão, obviamente, ser dirigidos aos alunos, na medida em que forem interpretando o referido mecanismo. Porém, entende-se que o docente tem o domínio para fazê-lo e que os livros didáticos, comumente usados nos cursos de graduação em Química Orgânica, atendem à referida demanda. No entanto, com a finalidade de despertar outros diálogos, de aprofundamento ou de contextualização, reflete-se que pode surgir uma série de questões interessantes, como, por exemplo, para o caso 1. Por volta de 1895 foi constatada a presença de paracetamol em pacientes que ingeriram fenacetina e acetanilida. Por que isso aconteceu? Ou, para o caso 2: como é utilizado o subproduto (glicerina) gerado na produção do biodiesel? Biocombustíveis são definitivamente a alternativa mais viável para o ambiente?

\subsection{Apreciação sobre o método dos casos}

Advindos das sete instituições de ensino superior que autorizaram a aplicação do questionário avaliativo sobre os casos, dez professores foram convidados a participar e cinco deles enviaram suas repostas. Os nomes dos professores e de suas respectivas instituições foram omitidos, neste trabalho, em virtude dos acordos de sigilo estabelecidos por meio do Comitê de Ética.

Para a questão Você utilizaria esse material (os casos) em suas aulas?, Quatro professores responderam que usariam e um respondeu que possivelmente usaria. Esses dados desencadearam surpresa, pois esperava-se maior resistência dos professores, diante de um material diferenciado e que requer outra atitude docente em sala de aula, como promover a investigação, mediar e incentivar os alunos na compreensão e busca da solução do caso. Essa aceitação se deu independentemente do tempo de docência ou da experiência com o método. Ao final do questionário, o item opcional comentários adicionais corroborou com esse indicativo: 
"Considero a iniciativa muito importante e de grande contribuição para o rompimento com o ensino livresco e repetitivo de mecanismos de reação (...)." (Professor 1; 17 anos de docência) docência)

"(....) saliento que utilizarei muitos deles em minhas aulas." (Professor 2; 5 anos de

Com relação à devolutiva para a pergunta Quais aspectos positivos e negativos você destacaria na aplicação desse método (casos)?, foi possível estabelecer as seguintes categorias de análise, apresentadas no Quadro 1.

Quadro 1: Aspectos positivos e negativos dos casos na percepção dos professores.

Aspectos Positivos

\begin{tabular}{c|c}
\hline Categorias & Incidência \\
\hline Atitudes ou Autonomia & 4 \\
\hline Contextualização & 3 \\
\hline Aluno no centro da aprendizagem & 2 \\
\hline Cotidiano & 1 \\
\hline
\end{tabular}

Aspectos Negativos

\begin{tabular}{c|c}
\hline Categorias & Incidência \\
\hline Tempo & 2 \\
\hline Restrições discentes & 4 \\
\hline Habilidade do professor & 3 \\
\hline Complexidade da reação & 1
\end{tabular}

Fonte: Elaborado pelos autores (2020).

Dentre os aspectos positivos dos casos, ganhou destaque, na percepção dos professores, o desenvolvimento da autonomia dos estudantes e de atitudes, como: busca; pesquisa; leitura, entre outras. Ademais, o método foi enaltecido por situar o aluno no centro do processo de ensino e aprendizagem. Os trechos, abaixo, reforçam essas características:

"Coloca o aluno como centro, o incentivando a buscar e propor soluções através do estudo e pesquisa de reações e métodos em Química Orgânica." (Professor 3)

“(...) desenvolve a autonomia, responsabilidade, ética, melhora a leitura, escrita e fala, motiva para pesquisa e melhora a autoestima do aluno (....)" (Professor 4) 
"Acredito que o aprendizado baseado em investigações se diferencia do tradicional por manter o aluno no centro do processo de aprendizagem. Isso resulta em um melhor aproveitamento dos conteúdos e permite que o conhecimento seja realmente adquirido." (Professor 1)

De fato, o método dos casos direciona o aluno à própria aprendizagem (MASSENA, FILHO E SÁ, 2013) e é comumente utilizado para desenvolver habilidades para a tomada de decisão (SÁ, 2006). Porém, ao longo da pesquisa de Sá (2006, p.11), e dentre vários estudos citados na sua obra, pôde-se evidenciar que os casos desencadeiam um rol de muitas outras habilidades, bastante significativas para beneficiar o processo de ensino, e também previstas pelos professores desta pesquisa, como o da comunicação oral e escrita, trabalho em grupo e pensamento crítico.

Foi favoravelmente ressaltada, ainda, a possibilidade de contextualização, sendo que o professor 2 também salientou a oportunidade de revelar o cotidiano, por meio do material.

"Alguns métodos podem ser de grande valia na contextualização, o material retrata situações cotidianas, o que é muito bom (...)." (Professor 2)

"Destaco a possibilidade de contextualização e de atribuição de significado ao estudo mecanístico." (Professor 5) (SIC)

Em concordância com a literatura, vê-se que, por meio dos casos, gera-se a oportunidade de disponibilizar aos alunos situações que dizem respeito, tanto ao conhecimento do conteúdo científico, quanto àquele sobre questões éticas, sociais e econômicas (SÁ; FRANCISCO; QUEIRÓZ, 2007). Em especial, na educação em Química, considerando-se, também, as divulgações da área, a abordagem investigativa é vista como uma estratégia que gera reações muito positivas nos alunos, como o interesse e compreensão pelas aulas de Química. Tal benefício, além dos já destacados, como o protagonismo do aluno, contextualização, articulação dos conceitos científicos com o cotidiano, entre outros, permite aos alunos terem uma melhor percepção do mundo que os cerca e verem, nas situações da vida real, que a Química da sala de aula está em ação (SCHABER, 2011; CAMPBELL, POWERS, ZHENG, 2016; CHOWDHURY, 2013; DIESEL, BALDEZ, MARTINS, 2017).

Diante desses apontamentos, percebe-se que os casos são potenciais como método de ensino e de aprendizagem e que, embora não se possa tecer observações nesta pesquisa sobre a aprendizagem de alunos, de acordo com os resultados obtidos 
em outros trabalhos, que utilizaram os casos no Ensino Superior, pode-se dizer que o ensinar e o aprender por investigação é reconhecido como um dos mais bem sucedidos métodos de aprendizagem, que vem se difundindo no meio acadêmico e, gradativamente, apresentando uma crescente utilização nas instituições de ensino (CHOWDHURY, 2013; SÁ; KASSEBOEHMER; QUEIROZ, 2013; SAMPAIO; BERNARDO; AMARAL, 2016).

Pode-se dizer que, se os estudos de caso forem aplicados em cursos de Licenciatura e em disciplinas de área específica, como a Química Orgânica, proporcionam o surgimento de uma metodologia relevante à prática docente, pois permitem que as dimensões pedagógicas e de conhecimento científico se tornem mais articuladas, resultando numa evolução de metodologia e construção do conhecimento, o que é bastante importante e oportuno para uma formação mais completa dos alunos. Portanto, prevê-se que o emprego de tal metodologia contribuirá para a formação de futuros docentes, beneficiando-os com uma visão mais ampla e consolidada da temática abordada e com maior domínio em investigação, comunicação, interpretação de dados e solução de problemas.

Além desses benefícios, os pontos negativos dos estudos de caso também foram previstos pelos professores (Quadro 1), porém, vale ressaltar que alguns dos docentes não veem esses aspectos necessariamente como negativos. Assim, houve proeminência das restrições advindas dos alunos, perante os casos, como resistir ou não, estar disposto a aderir ao método, timidez em dialogar ou, até mesmo, ficar assustado diante do primeiro contato com os casos. As respostas abaixo enunciam exemplos desses aspectos.

"(...) creio que, inicialmente, possa haver resistência por parte dos alunos que esperam um conteúdo pronto." (Professor 5)

[...] "como dito anteriormente, um ponto negativo e um desafio aos educadores que utilizam essa metodologia é fazer com que os alunos mais tímidos participem das discussões. Com minha pouca experiência percebi que eles ficam muito retraídos e para eles, acredito que o aprendizado não seja significativo com essas metodologias que precisam que esse aluno seja centro do processo e responsável pelo seu aprendizado." (Professor 1)

"Importante também deixar claro que quando se aplica uma metodologia como essa em um primeiro momento o aluno fica meio impactado, assustado (...)". (Professor 4) 
A habilidade do professor também foi um aspecto lembrado, por ser necessária para um adequado planejamento e aplicação do material, bem como saber motivar os alunos na busca pela solução do caso. Vejamos.

"Requer habilidade do professor para envolver TODOS os alunos nas discussões em sala de aula e criar um ambiente adequado para discussões frutíferas, com significado para o aprendizado efetivo". (Professor 3)

“(...) por isso a importância do planejamento e preparo do professor, que deve dar todo o suporte necessário para encorajar o estudante e o trabalho flua com leveza e o aluno se motive para buscar respostas. O aluno cresce muito quando é motivado a fazer parte do processo de construção do conhecimento". (Professor 4)

Por fim, foi relevante a preocupação com o tempo que é necessário conceder para a aplicação do método e com a complexidade que alguns mecanismos podem dispender, conforme podemos observar, nas expressões, a seguir.

“(...) porém nem todas as situações propostas podem ser utilizadas no curso, devido a falta de carga horária e disponibilidade dos alunos. Algumas situações problemas se tratam de reações um pouco complexas." (Professor 2)

"Uma das dificuldades é o tempo envolvido (não necessariamente um aspecto negativo)". (Professor 4)

Nessa perspectiva, embora os professores considerem os casos como uma estratégia bastante positiva, sua aplicabilidade, segundo eles, dependerá de uma série de fatores, incluindo, desde tempo, conteúdo e interesse dos alunos, até a familiarização e a adequada aplicação do método. Esses fatores surgem, inclusive, semelhantes aos constatados em estudos sobre metodologias ativas e/ou resolução por problemas divulgados na literatura.

Freire e Silva (2014), por exemplo, em pesquisa sobre a natureza das dificuldades na resolução de problemas de futuros professores de Química, discutem que existem, de fato, as dificuldades pedagógicas, devido à falta de experiência em realizar uma prática com perspectiva diferente. Para minimizar esse entrave, as autoras refletem que é importante assumir a necessidade de melhorar a formação inicial dos futuros docentes e de praticar, continuamente, a resolução de problemas, de modo que esse enfoque didático-pedagógico se torne a cultura nas aulas. Mesquita, Meneses e Ramos (2016, p. 478) também deixam claro que os professores precisam conhecer as teorias das propostas didáticas, para que reflitam mais criticamente sobre sua prática. Para tal, 
diagnosticaram a necessidade de mais encontros pedagógicos, ou seja, oferta de cursos de formação continuada e, também, a "promoção de discussões mais aprofundadas nas universidades acerca da possibilidade de transformações das ações educativas". (PONCE de LEON e SILVA, 2006.p.479.

As mesmas autoras também ressaltaram que a falta de tempo é um dos empecilhos para a aplicação de metodologias ativas, conforme apontado por dois professores, neste trabalho, diante dos casos, além da falta de articulação entre os conteúdos curriculares com a realidade. Ainda no estudo de Freire e Silva (2014, p. 33), menciona-se que o tempo "pode representar um complicador nas práticas conteudistas habituais que priorizam a quantidade ao invés da qualidade". No entanto, os pesquisados das autoras, para minimizar essa situação, propõem a seleção de problemas que envolvam "a maior quantidade possível de conteúdo".

Para os casos, o tempo é primordial, desde o preparo do professor até toda a condução dos alunos para o desenvolvimento e solução do caso, afinal, as informações devem ser buscadas, interpretadas e trocadas durante todo o processo. Uma possibilidade viável, no entanto, no Ensino Superior, é utilizar os casos como um recurso de avaliação, de modo que o professor vai acompanhando, com tutoria, nos horários de atendimento ao discente, a evolução do aluno ou do grupo de alunos, ao longo de dias e não necessariamente no horário de aula. Reserva-se, assim, apenas um momento para a socialização da solução e experiência vivenciada por todos.

Por fim, Mesquita e Ramos (2016), também observaram que a organização curricular é fundamental para que não haja desarticulação com a realidade ou, ainda, quando citam Saviani (2010), para que se tenha coerência entre o conteúdo solicitado e o tempo exigido. Nesse quesito, vale adicionar uma reflexão do professor 4 , que percebe a necessidade de reconstrução curricular dos cursos de graduação, visando contribuir com a aplicação de abordagens didáticas, como os casos: “(...) Cursos integrais ou disciplinas mais integradas e/ou interdisciplinares, que envolveriam mudanças curriculares, poderiam talvez, contribuir com este tipo de abordagens e melhorar a qualidade de ensino".

Com relação às apreensões dos alunos, como a resistência, a timidez ou o fato de ficarem assustados, podemos dizer que essas reações também são comuns em abordagens problematizadoras. No relato de Freire e Silva (2014), os participantes expressaram surpresa e preocupação diante de um problema exposto. Porém, as autoras notaram que, durante a resolução do problema, os alunos que não participaram da 
discussão geral se sentiram menos constrangidos em falar quando estavam em um grupo menor. Essa configuração pode ser uma solução para essa dificuldade, passando o professor a permitir a formação e a escolha dos grupos pelos discentes, a fim de que se sintam mais à vontade. Martins e colaboradores (2010, p. 17-18) ainda declaram que nem todos os estudantes estão preparados para novos métodos. Na pesquisa deles, sobre metodologias ativas, alguns alunos se sentiram inseguros e perdidos na busca do conhecimento e com "a sensação de que não sabem o que deveriam estar aprendendo, pelo menos inicialmente". Pela ótica desses alunos, houve uma mudança repentina do método, até então tradicional, e que tal transformação exigia mudança de comportamento, maturidade e organização. Nesse sentido, os autores evidenciaram que diante de métodos ativos, o estudante deve assumir esse papel de ser responsável pela própria aprendizagem e que a falta de familiaridade e de suporte adequado são aspectos de fragilidade para a implementação de novos modelos de ensino e aprendizagem.

Diante do exposto, revela-se a importância de que o professor lembre constantemente os alunos sobre os benefícios do método e, também, motive-os, auxiliando todos ao longo do processo de resolução dos casos, a fim de dar-Ihes mais confiança e desembaraço para participarem e evoluírem.

A implementação de metodologias ativas, como os casos, requer tempo, disponibilidade e, sobretudo, a vontade do profissional para modificar o seu fazer pedagógico (MESQUITA, MENESES E RAMOS, 2016). Nesse sentido, reitera-se a importância da formação continuada e/ou das capacitações docentes para o compartilhamento de conhecimentos a respeito das práticas educativas e para a busca de novas tendências pedagógicas (LIBÂNEO, 2009).

Para não deixarmos de comentar sobre o conteúdo de Química, exposto neste trabalho, destacamos que os professores evidenciaram que os fundamentos das reações químicas vieram à tona, ou seja, que ficou reconhecida a proficuidade dos casos para ensinar mecanismos de reação, conforme observações, a seguir:

"Entre os estudos de caso gostei muito da obtenção do biodiesel porque exige pensar não apenas nos reagentes e mecanismos, mas também nas condições da reação, que são essenciais para o êxito da reação" (Professor 5)

“(...) nestes materiais trazem questões que exploram conceitos importantes para o a compreensão dos mecanismos de reações: teorias ácido-base, uso de catalisadores, reagentes nucleófilos, o reagente em excesso, condições experimentais como a necessidade do controle de temperatura, o processo de purificação, possibilidade de tratamento dos resíduos entre outros (...)" (Professor 4) 


\section{CONSIDERAÇÕES FINAIS}

Mediante os resultados apresentados neste trabalho, é possível inferir que os professores avistaram, nos casos desenvolvidos, uma utilidade pedagógica e uma possibilidade real de estudar mecanismos de reação, em Química Orgânica, no Ensino Superior.

Os casos despontaram como relevantes no contexto do ensino e da aprendizagem, por motivarem uma metodologia ativa e trazerem mais realidade à sala de aula, situando o conteúdo dos casos em contextos relevantes e reais da profissão.

Ao mesmo tempo, é evidente que as familiaridades, suportes elou os desafios que a metodologia requer proporcionam mudanças nas posturas dos atores do processo de ensino e aprendizagem, pois o aluno deixa de ser passivo e o professor deixa de ser o centro do conhecimento.

Por fim, é importante registrar que os casos não restringem ou substituem outras metodologias de ensino, mas oferecem mais uma opção metodológica para fortalecer o processo educacional. A utilização diversificada de métodos deve ser estimulada e implementada, em favorecimento à aprendizagem e à completa formação dos estudantes.

\section{REFERÊNCIAS}

AZEVÊDO, L. C. de; REIS, M. M.; SILVA, L. A. da; ANDRADE, J. B. Efeito da presença e concentração de compostos carbonílicos na qualidade de vinhos. Química Nova, v. 30, n. 8, p. 1968,2007

BARBOSA, E. F.; MOURA, D. G. de. Metodologias ativas de aprendizagem na educação profissional e tecnológica. Boletim Técnico do Senac, v. 39, n. 2, p. 48-67, 2013.

BARDIN, L. Análise de Conteúdo. Lisboa: Edições 70, 1979. 225 p.

BENNETT, N.; CORNELY, K. Thalidomide makes a comeback: a case discussion exercise that integrates biochemistry and organic chemistry. Journal of Chemical Education, v. 78, n. 6, p. 759, 2001.

BOUD, D.; FELETTI, G. Changing problem-based learning: Introduction to the second edition. In: - The challenge of problem-based learning. Londres: Kogan Page, 2 ed. p. $1-14,1997$

BRASIL. Ministério da Educação. Conselho Nacional de Educação. Câmara De Educação Superior. Diretrizes Curriculares Nacionais para os Cursos de Química. Resolução CNE/CES 1.303/2001. Diário Oficial da União, 2001.

BRUICE, P. Y. Química Orgânica. 4. ed. v.2. São Paulo: Pearson Prentice Hall, 2006. 
CAMPBELL, M.; POWERS, T. M.; ZHENG, S. Teaching with the case study method to promote active learning in a small molecule crystallography course for chemistry students. Journal of Chemical Education, v. 93, n. 2, p. 270-274, 2016.

CARVALHO, A. M. P. de. O Ensino de Ciências: unindo a pesquisa e a prática. São Paulo: Pioneita Thomson Learning Editores, 2004.

CHIAVENATO, I. Princípios da administração: o essencial em teoria geral da administração. 2. ed. São Paulo: Editora Manole, 2006.

CHOWDHURY, M. A. Incorporating a soap industry case study to motivate and engage students in the chemistry of daily life. Journal of Chemical Education, v. 90, n. 7, p. 866872, 2013.

CLIFF, W. H.; CURTIN, L. N. The directed case method. Journal of College Science Teaching, v. 30, n. 1, p. 64-66, 2000.

CLISSOLD, S. P. Paracetamol e fenacetina. Drogas, v. 32, n. 4, p. 46-59, 1986.

DA SILVA, J. A. O sujeito psicológico e o tempo da aprendizagem. Cadernos de Educação| FaE/PPGE/UFPel| Pelotas, v. 32, p. 229-250, 2009.

DIESEL, A.; BALDEZ, A. L. S.; MARTINS, S. N. Os princípios das metodologias ativas de ensino: uma abordagem teórica. Revista Thema, v. 14, n. 1, p. 268-288, 2017.

FREIRE, M. S.; SILVA, M. G. L. Vivenciando a estratégia de resolução de problemas: dificuldades de futuros professores de química. Educação Química, v. 25, n. 1, p.30-34, 2014.

FREITAS, R. A. M. da M. Ensino por problemas: uma abordagem para o desenvolvimento do aluno. Educação e Pesquisa, v. 38, n. 2, p. 403-418, 2012.

GRUPO DE PESQUISA EM ENSINO DE QUÍMICA DO IQSC. Casos Investigativos. Disponível em: < http://www.gpeqsc.com.br/>. Acesso em 30 jun. 2019.

HERREID, C. F. Sorting potatoes for Miss Bonner. Journal of college science teaching, v. 27, n. 4 , p. 236-239, 1998.

HERREID, C. F. Can case studies be used to teach critical thinking? Journal of College Science Teaching, v. 33, n. 6, p. 12-14, 2004.

HERREID, C. F. Using Case Studies to Teach Science. Education: Classroom Methodology. American Institute of Biological Sciences, 2005.

HERREID, C. F. Start with a story: The case study method of teaching college science. NSTA press, 2007.

LEITE, L.; AFONSO, A. Aprendizagem baseada na resolução de problemas. Características, organização e supervisão. Boletín das Ciencias, 48, 253-260, 2001.

LIBÂNEO, J. C. Democratização da escola pública: a pedagogia crítico-social dos conteúdos. 23. ed. São Paulo: Loyola, 2009. 
MARIN, M. J. S.; LIMA, E. F. G.; PAVIOTTI, A. B.; MATSUYAMA, D. T.; SILVA, L. K. D.; GONZALEZ, C.; DRUZIAN, S.; ILIAS, M. Aspectos das fortalezas e fragilidades no uso das metodologias ativas de aprendizagem, Revista Brasileira de Educação Médica, v. 34, n. 1, p. 13-20, 2010.

MASSENA, E. P.; GUZZI FILHO, N. J.; SÁ, L. P. Produção de casos para o ensino de Química: uma experiência na formação inicial de professores. Química Nova, v. 36, n. 7, p. 1066-1072, 2013.

MESQUITA, S. K. da C.; MENESES, R. M. V.; RAMOS, D. K. R. Metodologias ativas de ensino/aprendizagem: dificuldades de docentes de um curso de enfermagem. Trabalho, Educação e Saúde, v. 14, n. 2, p. 473-486, 2016.

MORESI, E. et al. Metodologia da pesquisa. Brasília: Universidade Católica de Brasília, v. 108, p. $24,2003$.

NICOLINE, A. Qual será o futuro das fábricas de administradores? Revista de Administração de Empresas, v. 43, n. 2, p. 44-54, 2003.

PÁDUA, E. M. M. Metodologia de pesquisa: Abordagem teórico-prática. CampinasSP: Papirus, 1997.

PASSOS, K. dos. Estudo de Casos sobre a química dos carboidratos: contribuições para a formação profissional dos estudantes de química da UFRGS. XVIII Encontro Nacional de Ensino de Química, 2016.

PÉREZ, D. G. Contribución de la historia y de la filosofía de las ciencias al desarrollo de un modelo de enseñanza/aprendizaje como investigación. Enseñanza de las Ciencias, v. 11, n. 2, p. 197-212, 1993.

PERRENOUD, P. A formação dos professores no século XXI. In: PERRENOUD, P. et al. As competências para ensinar no século $\mathbf{X X I}$ : A formação dos professores e o desafio da avaliação. Porto Alegre: Artmed, 2002. p. 11-34.

RINGAN, N. S.; GRAYSON, L. Molecular Modelling in the Undergraduate Chemistry Curriculum: The Use of beta-Lactams as a Case Study. Journal of chemical education, v. 71, n. 10 , p. 856,1994

SÁ, L. P. A argumentação no ensino superior de química: investigando uma atividade fundamentada em estudos de casos. 153 f. Dissertação (Mestrado em Química Analítica) - Instituto de Química de São Carlos, São Carlos, 2006.

SÁ, L. P.; FRANCISCO C. A.; QUEIROZ S. L. Estudos de caso em química. Química Nova, v. 30, n. 3, p. 731, 2007.

SÁ, L. P.; KASSEBOEHMER, A. C.; QUEIROZ, S. L. Casos investigativos de caráter sociocientífico: aplicação no ensino superior de Química. Educación Química, v. 24, p. 522-528, 2013.

SÁ, L. P.; QUEIROZ, S. L. Estudo de casos no ensino de química. Campinas: Editora Átomo, 2010. 
SAVIANI, D. Interlocuções pedagógicas: conversas com Paulo Freire e Adriano Nogueira e 30 entrevistas sobre educação. São Paulo: Autores Associados, 2010.

SCHABER, P. M. et al. Juicing the juice: A laboratory-based case study for an instrumental analytical chemistry course. Journal of Chemical Education, v. 88, n. 4, p. 496-498, 2011.

SILVA, S. F.; NÚÑEZ, I. B. O ensino por problemas e trabalho experimental dos estudantes-reflexões teórico-metodológicas. Química Nova, v. 25, n. 6/B, p. 1197-1203, 2002.

SOUZA, S. C. de; DOURADO, L. Aprendizagem baseada em problemas (ABP): um método de aprendizagem inovador para o ensino educativo. Holos, v. 5, p. 182-200, 2015.

TÄRNVIK, A. The multiple-case method. Journal of College Science Teaching, v. 32, n. 2, p. 94-97, 2002.

VOLHARDT, P.; SCHORE, N. Química Orgânica: estrutura e função. 6. ed. Porto Alegre: Bookman, 2013.

WARTHA, E. J.; LEMOS, M. M. Abordagens investigativas no ensino de Química: limites e possibilidades. Amazônia: Revista de Educação em Ciências e Matemáticas, v. 12, n. 24, p. 5-13, 2016.

ZABALA, A.; ARNAU, L. Como aprender e ensinar competências. Porto Alegre: Artmed, 2010. 